Bull. Mater. Sci., Vol. 16, No. 6, December 1993, pp. 583-599. (C) Printed in India.

\title{
The unique features of textures in low-carbon steels
}

\author{
SANAK MISHRA \\ R \& D Centre for Iron \& Steel, Steel Authority of India Limited, Ranchi 834 002, India
}

\begin{abstract}
Textures in low-carbon steels are of great significance in view of their strong influence on important physical properties such as formability and magnetic induction. Recent studies on the formation and evolution of textures through different processing stages of hot rolling, cold rolling and annealing have brought out many unique features, e.g. presence of complete and almost ideal fibre axes, inheritance of texture, texture memory effect and parallels between single crystal and polycrystalline situations. In particular, it has been possible to develop a fairly cogent picture of the genesis and perpetuation of the Goss texture.
\end{abstract}

Keywords. Low-carbon steel; textures; silicon steel.

\section{Introduction}

Preferred orientation of grains or texture is a very interesting topic of study in the case of low-carbon steels, in view of the strong bearing it has on physical characteristics such as deep drawability (Mishra and Därmann 1982; Hutchinson 1984; Mishra 1990) and electromagnetic properties (Goss 1935; Bozorth 1935; Mishra 1984; Mishra et al 1984, 1986; Matsuo 1989; Mishra 1993). Control of texture in industrial processing has therefore, assumed great significance.

Particularly during the last decade, much progress has taken place in advancing our knowledge of textures in low-carbon steels, primarily on account of the application of superior research techniques like the ODF (orientation distribution function) analysis. It might be mentioned that early researches on textures were invariably carried out by the pole figure method, wherein basically $\mathrm{X}$-ray reflection intensities of selected planes were obtained. For more quantitative determination of textures, Roe $(1965)$ and Bunge $(1965,1969)$ independently developed the ODF analysis. In the Bunge formalism the orientation $g$ of a crystallite is specified with respect to its specimen coordinate system (rolling direction RD, transverse direction $T D$, and normal direction ND) by the three Eulerean angles $\phi_{1}, \phi$ and $\phi_{2}$ (figure 1). The ODF $f(g)$ is calculated from measured pole densities of at least three incomplete pole figures by means of series expansion into spherical harmonics. Although there are certain drawbacks of the series expansion method, the information contained in ODFs is still much more extensive and more detailed than that which can be derived from the pole figures themselves.

ODFs are generally presented in the form of contour lines of equal intensity in $\phi_{1}=$ constant sections (e.g. $\phi_{1}=0^{\circ}, 5^{\circ}, \ldots 90^{\circ}$ ) through the Euler angle space. Each section carries the locations of many important orientations, as in figure 2 . Since bcc metals like deep drawing steels and silicon steels exhibit, besides discrete peak-type components, very strong fibre-type components or orientation tubes as textural elements, Mishra and coworkers (Mishra 1983; Mishra et al 1983, 1984a, b, 1986; Därmann et al 1984) who used the ODF analysis extensively, have developed a 


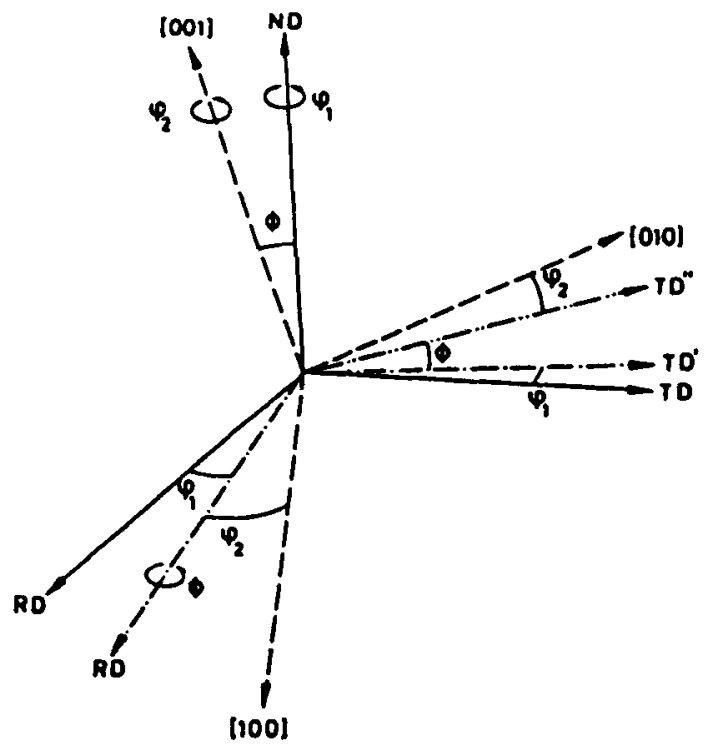

Figure 1. Definition of Euler angles used in ODF technique (Bunge 1965).
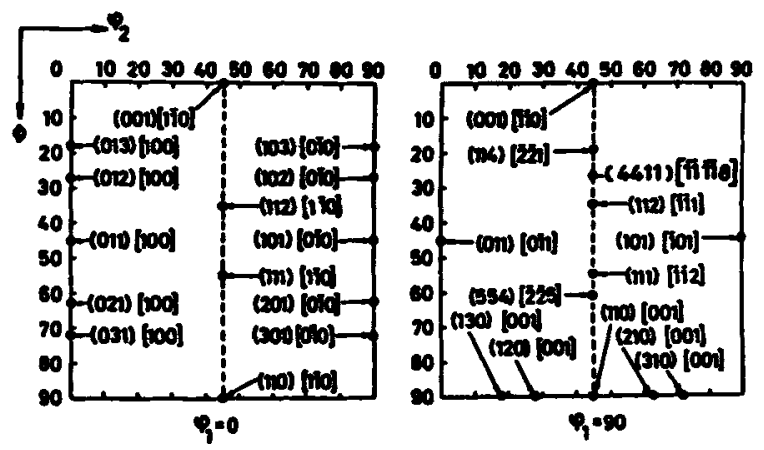

Figure 2. Location of certain ideal orientations in Euler space (Mishra 1984a).

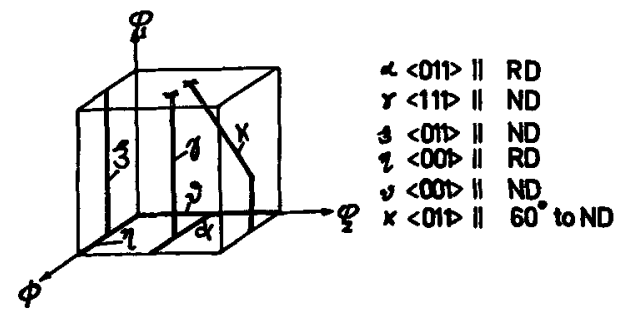

Figure 3. Positions of most important lines in Euler space for description of ODFs. Symmetrically equivalent lines have been left out; only one of them is shown. See table 1 for detailed crystallographic description (Mishra et al 1986). 
Table 1. Description of lines shown in Euler space in figure 3 (Mishra et al 1986).

$x \quad$ The line parallel to $\phi$ axis, specified by $\varphi_{1}=0 \mathrm{deg}$ and $\varphi_{2}=45 \mathrm{deg}$; corresponding to orientations obtained by a rotation around the $\langle 110\rangle$ axis parallel to rolling direction RD, e.g. from (001)[1 10 ] at $\phi=0 \mathrm{deg}$ to $(110)[1 \overline{1} 0]$ at $\phi=90 \mathrm{deg}$, rotation around [1 $\overline{1} 0]$.

$\eta \quad$ Line $\| \varphi_{1}$ for $\phi=55 \mathrm{deg}, \varphi_{2}=45 \mathrm{deg}$; rotation around $\langle 111\rangle \| N D$, e.g. from(111)[110] at $\varphi_{1}=0$ deg to (111)[112] at $\varphi_{1}=90 \mathrm{deg}$, rotation around [111].

$\zeta \quad$ Line $\| \varphi_{1}$ at $\phi=45 \mathrm{deg}, \varphi_{2}=0 \mathrm{deg}$; rotation around $\langle 011\rangle \| N D$, e.g. from $(011)[100]$ at $\varphi_{1}=0$ deg to $(011)[0 \overline{1} 1]$ at $\varphi_{1}=90 \mathrm{deg}$, rotation around [011].

$\kappa \quad$ Line $\|\langle 011\rangle$ axis inclined at $60 \mathrm{deg}$ to $N D$ in the plane $N D / R D$, e.g. from $(101)[\overline{1} 21]$ at $\varphi_{1}=35 \mathrm{deg}$, $\phi=45 \mathrm{deg}, \varphi_{2}=90 \mathrm{deg}$ to near (4411)[11118] at $\varphi_{1}=90 \mathrm{deg}, \phi=27 \mathrm{deg}$ and $\varphi_{2}=45 \mathrm{deg}$, rotation around [011].

$\eta \quad$ Line $\| \phi$ at $\varphi_{1}=0 \mathrm{deg}, \varphi_{2}=0 \mathrm{deg}$; rotation around $\langle 001\rangle \| \mathrm{RD}$, e.g. from (001)[100] at $\varphi_{1}=0$ deg, $\phi=0 \mathrm{deg}, \varphi_{2}=0 \mathrm{deg}$, to (010)[100], rotation around [100].

v Line $\| \varphi_{2}$ at $\varphi_{1}=0 \mathrm{deg}, \phi=0 \mathrm{deg}$; rotation around $\langle 001\rangle \| \mathrm{ND}$, e.g. from $(001)[100]$ to $(001)[0 \overline{1} 0]$, rotation around [001].

description system for the fibres (figure 3, table 1) which is suitable for interpreting the preferred orientations.

In this paper an overview is presented on the current level of understanding of textures in deep drawing steels and grain-oriented silicon steels, both of which have attracted considerable attention from scientists in recent times. Several new concepts on texture formation that have emerged will also be touched upon.

\section{Special features of textures in deep drawing steels}

Low-carbon steels find large-scale use in deep drawing applications, especially in press-forming of automotive components which sometimes have very complex shapes (figure 4). Whiteley (1960) demonstrated conclusively that crystallographic texture is the most important material property influencing the performance of ductile materials in deep drawing and that the drawability of suitably textured sheets is superior to that

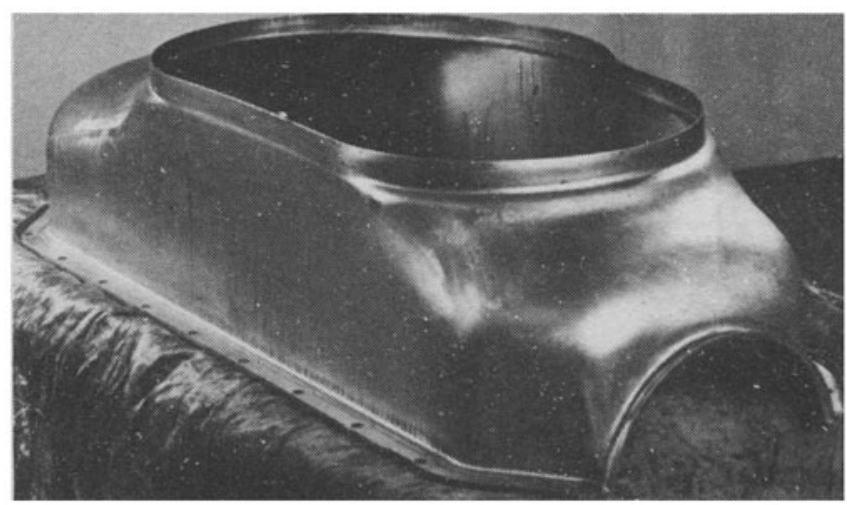

Figure 4. Automobile component press-formed from extra deep drawing quality sheet steel (Mishra 1990). 
of isotropic material. Earlier, Lankford et al (1950) had already shown that preferred orientation of grains influenced the plastic anisotropy of sheet steels, designated by the parameter $\bar{r}$. Measurements by Whiteley et al (1961) clearly indicated that the higher the $\bar{r}$ values, the deeper is the draw. By now it has been clearly established (Mishra and Därmann 1982; Mishra 1983; Mishra et al 1983; Hutchinson and Ushioda 1984; Hutchinson 1984; Mishra 1990) that in box-annealed or continuously annealed aluminium-killed steels, which by far constitute the largest proportion of commercially available deep drawing steels, the most desirable texture for achieving high $\boldsymbol{r}$ values around $1 \cdot 6-2 \cdot 0$ is the $\{111\}\langle 110\rangle$ type cube-on-corner texture (figure 5). When the steel is alloyed with around $0.1 \%$ phosphorous, higher $\bar{r}$ values $(>2)$ can be attained (Hu 1978) with a sharp $\{111\}\langle 112\rangle$ texture. In the case of interstitial-free Ti-stabilized (Lotter et al 1978) or Nb-stabilized (Willis and Hatherly 1976) steels, their high $\bar{r}$ values (up to 2.5 ) are associated with either sharp $\{111<112\}$ or $\{554\}<225\rangle$ textures which are crystallographically very close to each other. The new class of bake-

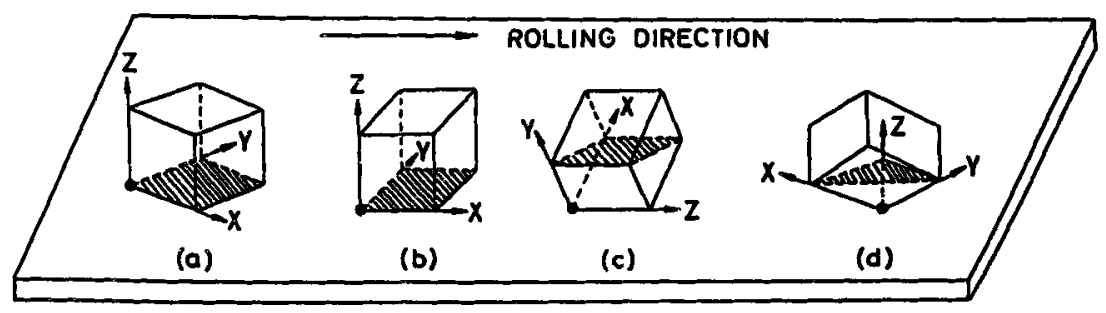
(a) Deformation Texture : (001) [110]
(b) Cube Texture : (001) [100)
(c) Cube-on-edge Texture : (110) 1001]
(d) Cube-on-corner Texture : (III) [īo]

Figure 5. Some common texture components observed in low-carbon sheet steel (Mishra and Därmann 1982).

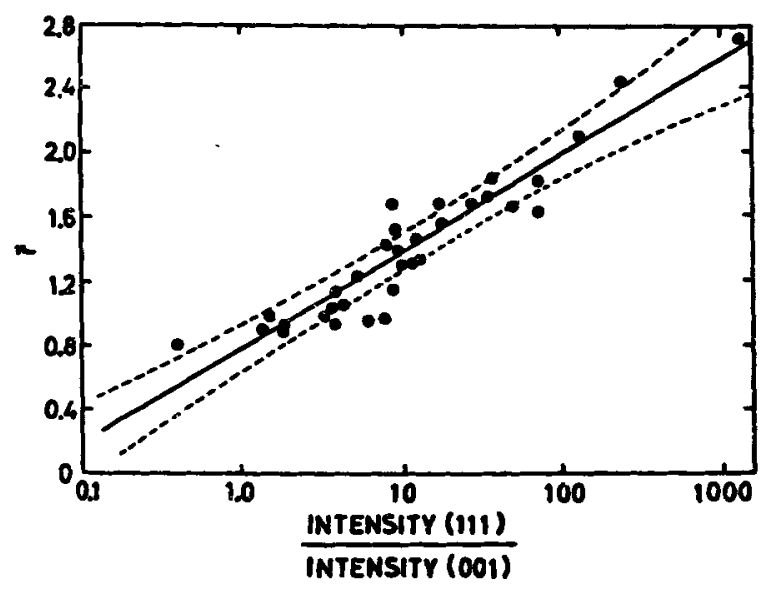

Figure 6. Approximate linear relationship between $\bar{r}$ and $\{111\} /\{001\}$ intensity ratio, measured using inverse pole figure technique (Held 1965). 


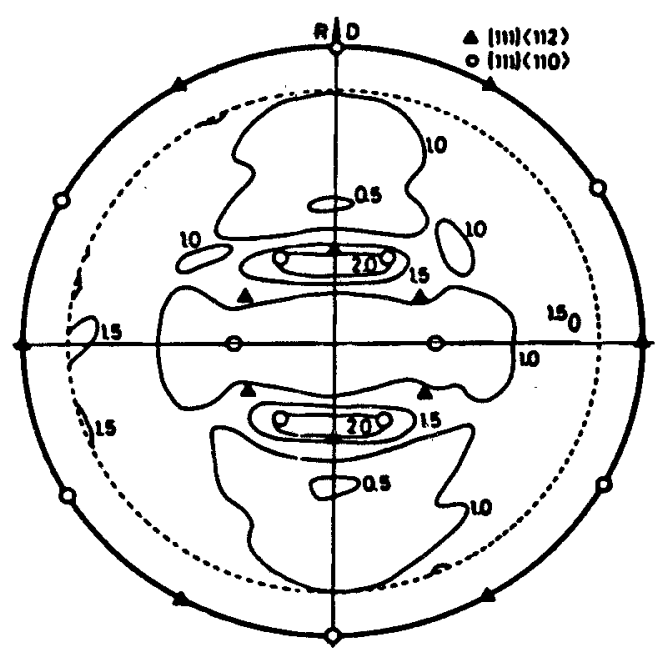

Figure 7. (110) pole figure for boron-treated steel. Triangles indicate ideal positions of $\{111\}\langle 112\rangle$ and circles those of $\{111\}\langle 110\rangle$ (Mishra et al 1983).

hardenable steels produced by continuous annealing also exhibit (Irie et al 1982) a sharp $\{111\}$ type texture.

Whiteley and Wise (1962), and subsequently Held (1965) (figure 6), showed a positive linear relationship between $\{111\}$ type texture component and $\bar{r}$, and simultaneously a negative contribution from the $\{100\}$ component. The work of Mishra and coworkers (Mishra 1984; Mishra et al 1985) on aluminium-killed steels suggested further that higher $r$ values were also associated with higher intensity of the $\{112\}$ component, in combination with a lower intensity of the $\{110\}$ component.

As already mentioned, the ODF analysis is a powerful tool for carrying out quantitative texture evaluation. Such analysis of recrystallization textures (after $70 \%$ cold rolling) was carried out by Mishra et al (1983) in the case of a low-carbon borontreated steel of moderate formability $(\bar{r}=1 \cdot 3)$ and by Mishra (1983) of an aluminiumkilled steel of excellent formability $(\bar{r}=1 \cdot 6)$. In the former case, a successful attempt was also made (for the first time in the literature for a bcc metal) to estimate quantitatively the volume fraction of textural components present in the specimen.

As seen in figure 7 , the pole figure of the boron-treated steel is rather flat and smeared out. In contrast, the ODF for the same steel (figure 8) exhibits pronounced maxima in orientation space. This is a classic example of the much-enhanced resolution of textural components that can be achieved with the ODF vis-a-vis the pole figure.

Considering first the intensity peaks in the ODF in figure 8, one finds that the strongest component is the $\{111\}\langle 110\rangle$. It is seen further (figures 9 and 10) that the $\{111\}\langle 110\rangle$ is in fact a part of an almost ideal $\langle 111\rangle \| N D$ fibre, or orientation tube,

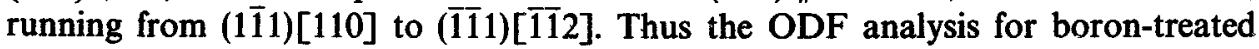
steel here provided the first unambiguous and clear-cut documentation of the complete $\langle 111\rangle \| N D$ fibre axis in deep drawing steels. Mishra (1983) also observed an almost identical fibre axis in his study of aluminium-killed deep drawing steel (a notable difference was that in the latter steel the strength, i.e. orientation density, of the $\langle 111\rangle$ fibre was higher, which explains its higher $r$ value). In fact the $\langle 111\rangle \| N D$ fibre 


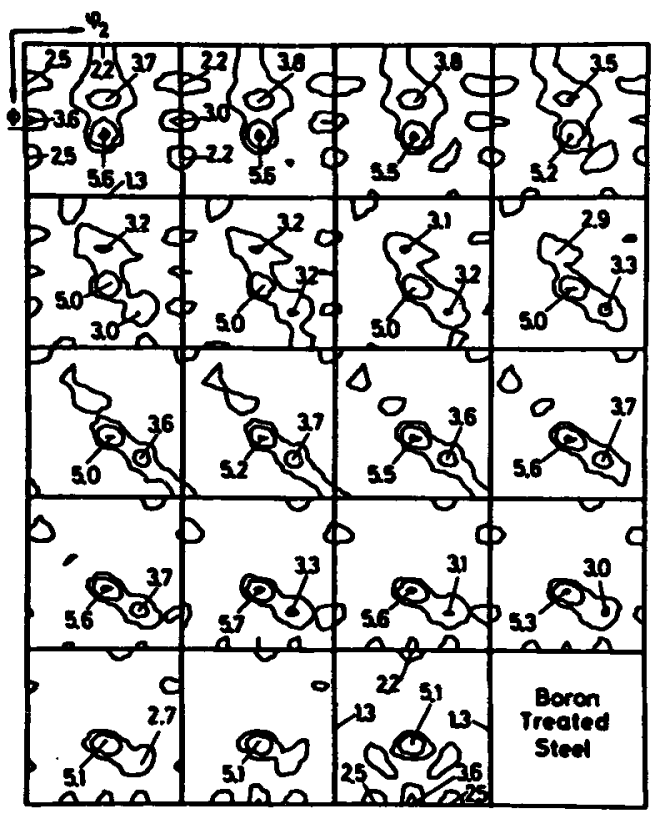

Figure 8. Orientation density function $f(g)$ for steel of figure 7, represented in sections at constant $\phi_{1}$ values $\left(\phi_{1}=0^{\circ}, 5^{\circ}, \ldots, 90^{\circ}\right)$. In each section $\phi$ and $\phi_{2}$ vary from $0^{\circ}$ to $90^{\circ}$. Contour lines are for intensity ratios 1·5, 3 and 5 times random intensity (Mishra et al 1983).

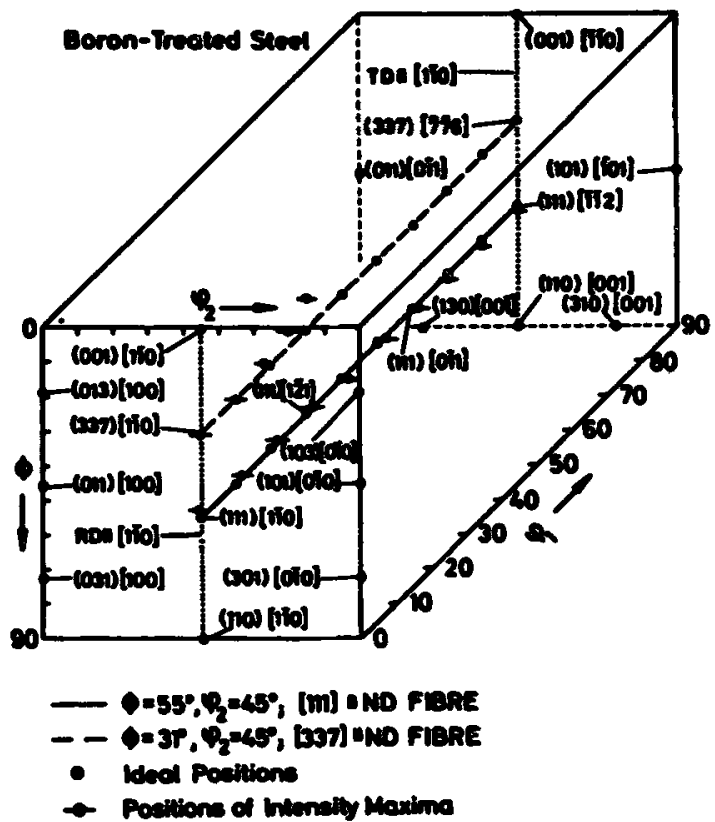

Figure 9. Skeleton lines for the strongest and the second-strongest intensity maxima for steel of figures 7 and 8 (Mishra et al 1983), also shown are locations of ideal orientations. 

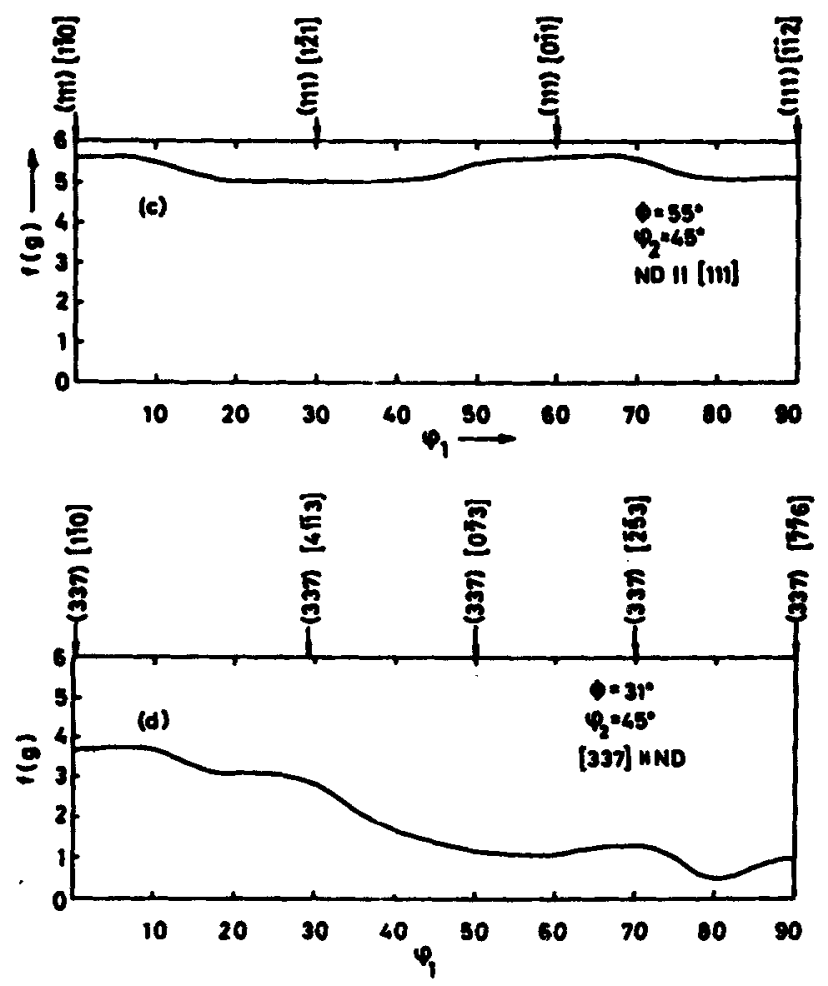

Figure 10. Variation of orientation density along lines specified by $\langle 111\rangle \| N D$ and $\langle 337\rangle \| N D$, for steel of figures 7.8 and 9 (Mishra et al 1983).

appears to be a general feature in the recrystallization textures of many deep drawing steels (see Mishra 1983).

It may be noted in figures 9 and 10 that apart from the $\langle 111\rangle \|$ ND fibre, another major component is a limited (incomplete) fibre-centred around $\langle 337\rangle \| N D$, with highest intensity at (337)[110]. Amongst other components (minor) in this steel (figure 8) are $\{110\}\langle 001\rangle$ and $\{001\}\langle 110\rangle$. These textural components were also seen in similar fashion in the Al-killed steel (Mishra 1983). A detailed analysis of the texture profile of this steel is presented in table 2 , in view of its wide applications.

Clearly in deep drawing steels the following two concepts have to be used in describing the textural features: (a) peak type components, i.e. more or less isotropic scattering ranges around certain ideal orientation, e.g. $\{110\}\langle 001\rangle$ and (b) complete, e.g. $\langle 111\rangle \| N D$, and incomplete, e.g. $\langle 337\rangle \| N D$, orientation tubes or fibres.

\section{The unique features of texture evolution in silicon steels}

To Goss (1935) goes the credit of inventing Fe-3.5\% Si steel sheets with very superior magnetic properties for use in transformer cores. However, it was Bozorth (1935) who showed that the excellent magnetic properties achieved by Goss were on account of a sharp texture, being of $\{011\}\langle 100\rangle$ cube-on-edge type. This was subsequently termed as the Goss texture. For almost sixty years now, the genesis and perfection 
Table 2. Textural component in aluminium-killed steel (Mishra 1983).

\begin{tabular}{|c|c|c|c|c|c|c|c|}
\hline \multirow[b]{2}{*}{ Component } & \multicolumn{4}{|c|}{$\begin{array}{l}\text { Ideal positions of equivalent } \\
\text { orientations }\end{array}$} & \multirow[b]{2}{*}{$f(g)$} & \multirow[b]{2}{*}{$i$} & \multirow[b]{2}{*}{$f(g)$, } \\
\hline & Orientation & $\phi_{1}$ & $\phi$ & $\phi_{2}$ & & & \\
\hline$\{110\}\langle 110\rangle$ & $\begin{array}{l}(110)[0 \overline{1} 1] \\
(111)[110]\end{array}$ & $\begin{array}{r}60 \\
0\end{array}$ & $\begin{array}{l}55 \\
55\end{array}$ & $\begin{array}{l}45 \\
45\end{array}$ & 6.0 & 48 & 3.00 \\
\hline$\{111\}\langle 112\rangle$ & $\begin{array}{l}(111)[\overline{11} 2] \\
(111)[121]\end{array}$ & $\begin{array}{l}90 \\
30\end{array}$ & $\begin{array}{l}55 \\
55\end{array}$ & $\begin{array}{l}45 \\
45\end{array}$ & 5.5 & 48 & $2 \cdot 25$ \\
\hline$\{337\}\langle 110\rangle^{*}$ & $\begin{array}{l}(337)[1 \overline{1} 0] \\
(733)[011]\end{array}$ & $\begin{array}{r}0 \\
49\end{array}$ & $\begin{array}{l}31 \\
68\end{array}$ & $\begin{array}{l}45 \\
67\end{array}$ & $3 \cdot 9$ & 48 & 1.95 \\
\hline$\{001\}\langle 110\rangle$ & $\begin{array}{r}@(001)[1 \overline{1} 0] \\
\$(001)[\overline{11} 0] \\
(010)[101] \\
(100)[0 \overline{1} 1]\end{array}$ & $\begin{array}{r}0 \\
90 \\
45 \\
45\end{array}$ & $\begin{array}{r}0 \\
0 \\
90 \\
90\end{array}$ & $\begin{array}{r}45 \\
45 \\
0 \\
90\end{array}$ & $2 \cdot 9$ & 24 & $0-71$ \\
\hline$\{210\}\langle 001\rangle$ & $\begin{array}{l}(012)[100] \\
(021)[100] \\
(102)[010] \\
(201)[010] \\
(120)[001] \\
(210)[001] \\
(011)[100]\end{array}$ & $\begin{array}{r}0 \\
0 \\
0 \\
0 \\
90 \\
90 \\
0\end{array}$ & $\begin{array}{l}27 \\
63 \\
27 \\
63 \\
90 \\
90 \\
45\end{array}$ & $\begin{array}{r}0 \\
0 \\
90 \\
90 \\
27 \\
63 \\
0\end{array}$ & $2 \cdot 1$ & 48 & 1.05 \\
\hline$\{110\}\langle 001\rangle$ & $\begin{array}{l}(110)[001] \\
(101)[0 \overline{1} 0]\end{array}$ & $\begin{array}{r}90 \\
0\end{array}$ & $\begin{array}{l}90 \\
45\end{array}$ & $\begin{array}{l}45 \\
90\end{array}$ & 1.8 & 24 & 0.45 \\
\hline$\{441\}\langle 110\rangle$ & $\begin{array}{l}(441)[110] \\
(144)[0 \overline{1} 1]\end{array}$ & $\begin{array}{r}0 \\
80\end{array}$ & $\begin{array}{l}80 \\
46\end{array}$ & $\begin{array}{l}45 \\
14\end{array}$ & $1 \cdot 3$ & 48 & 0.65 \\
\hline
\end{tabular}

$f(g)$ maximum in intensity occurring at or near to an ideal orientation.

$i$ multiplicity (of orientations).

$f(g), f(g) / i=$ reduced intensity.

* Close to $\{112\}\langle 110\rangle$ for which the equivalent orientations (112)[110] and (211)[011] occur, respectively, at $\phi_{1}=0, \phi=35, \phi_{2}=45^{\circ}$ and $\phi_{1}=51$, $\phi=66, \phi_{2}=63^{\circ}$.

(a) Also occurs for other positions specified by $\phi_{1}+\phi_{2}=45^{\circ}, \phi=0^{\circ}$.

$\$$ Also occurs for other positions specified by $\phi_{1}+\phi_{2}=135^{\circ}, \phi=0^{\circ}$.

of the Goss texture has remained of great fundamental interest. References to most of the important studies on this subject can be found in Mishra et al (1984a) and Mishra (1993) as also Matsuo (1989).

It was Dunn (1949) who first pointed out that the Goss texture develops by a process of secondary recrystallization, which generally leads to abnormal grain growth and hence large grain sizes. Beck (1954) established that the precondition for secondary recrystallization is a small primary grain size arrived at through the inhibition of normal grain growth either by second phase particles (impurity inhibition) or by the presence itself of a sharp primary recrystallization texture (texture inhibition). Subsequently May and Turnbull (1958) showed that for the type of grain-oriented silicon steel produced around that time, secondary recrystallization was linked with impurity inhibition caused by a fine dispersion of $\mathrm{MnS}$ precipitates. 
Table 3. Different manufacturing processes for grain-oriented silicon steels (Matsuo 1989).

\begin{tabular}{|c|c|c|c|}
\hline \multirow[b]{2}{*}{ Conventional grades } & \multicolumn{3}{|c|}{ High permeability grades } \\
\hline & Type 1 & Type 2 & Type 3 \\
\hline $\begin{array}{l}\text { Steelmaking } \\
\text { microalloy } \\
(\mathrm{MnS})\end{array}$ & $\begin{array}{l}\text { Steelmaking } \\
\quad \text { microalloy } \\
(\mathrm{AlN}+\mathrm{MnS})\end{array}$ & $\begin{array}{l}\text { Steelmaking } \\
\text { microalloy } \\
(\mathrm{MnSe}+\mathrm{Sb}, \mathrm{Mo})\end{array}$ & $\begin{array}{l}\text { Steelmaking } \\
\text { microalloy } \\
(B+N+S \text { or } \mathrm{Se})\end{array}$ \\
\hline $\begin{array}{l}\text { Hot rolling } \\
\text { reheating } \\
(1593 \mathrm{~K})\end{array}$ & $\begin{array}{l}\text { Hot rolling } \\
\text { reheating } \\
(1633 \mathrm{~K})\end{array}$ & $\begin{array}{l}\text { Hot rolling } \\
\text { reheating } \\
(1593 \mathrm{~K})\end{array}$ & $\begin{array}{l}\text { Hot rolling } \\
\text { reheating } \\
(1523 \mathrm{~K})\end{array}$ \\
\hline $\begin{array}{l}\text { Annealing } \\
\quad(1073-1273 \mathrm{~K})\end{array}$ & $\begin{array}{l}\text { Annealing } \\
(1373 \mathrm{~K})\end{array}$ & $\begin{array}{r}\text { Annealing } \\
(1173 \mathrm{~K})\end{array}$ & $\begin{array}{l}\text { Annealing } \\
\qquad(1148-1298 \mathrm{~K})\end{array}$ \\
\hline $\begin{array}{l}\text { Cold rolling } \\
(70 \%)\end{array}$ & $\begin{array}{l}\text { Cold rolling } \\
(87 \%)\end{array}$ & Cold rolling & $\begin{array}{l}\text { Cold rolling } \\
\left(80^{\circ} \%\right)\end{array}$ \\
\hline $\begin{array}{l}\text { Annealing } \\
\qquad(1073-1273 \mathrm{~K})\end{array}$ & & Annealing & \\
\hline $\begin{array}{l}\text { Cold rolling } \\
(55 \%)\end{array}$ & & $\begin{array}{l}\text { Cold rolling } \\
(65 \%)\end{array}$ & \\
\hline $\begin{array}{l}\text { Decarburising } \\
\left(1073 \mathrm{~K} \text {, wet } \mathrm{H}_{2}+\mathrm{N}_{2}\right)\end{array}$ & Decarburising & Decarburising & Decarburising \\
\hline $\begin{array}{l}\text { Box annealing } \\
\left(1473 \mathrm{~K} \text {, dry } \mathrm{H}_{2}\right)\end{array}$ & $\begin{array}{l}\text { Box annealing } \\
(1473 \mathrm{~K})\end{array}$ & $\begin{array}{l}\text { Box annealing } \\
(1093-1173 \mathrm{~K} \text {, then } \\
\left.1473 \mathrm{~K} \text {, dry } \mathrm{H}_{2}\right)\end{array}$ & $\begin{array}{l}\text { Box annealing } \\
(1473 \mathrm{~K})\end{array}$ \\
\hline
\end{tabular}

Whereas impurity inhibition remains the major technique of manufacture of oriented silicon steels till today, systems other than $\mathrm{MnS}$ (or in combination with it) have come into use (table 3 ) leading to a very high degree of perfection in grain orientation. There are two principal grades commercially available at present: conventional or regular material (described in the literature as RM, RGO, or CGO) and high permeability material (HM, HGO). The high permeability steels are characterized by an average misorientation of the $\langle 001\rangle$ axis from the rolling direction by 3-4 degrees as against about 7 degrees in conventional steels (figure 11). It may also be noted from table 3 that the manufacturing process for the RGO and the type 2 HGO involve a two-stage
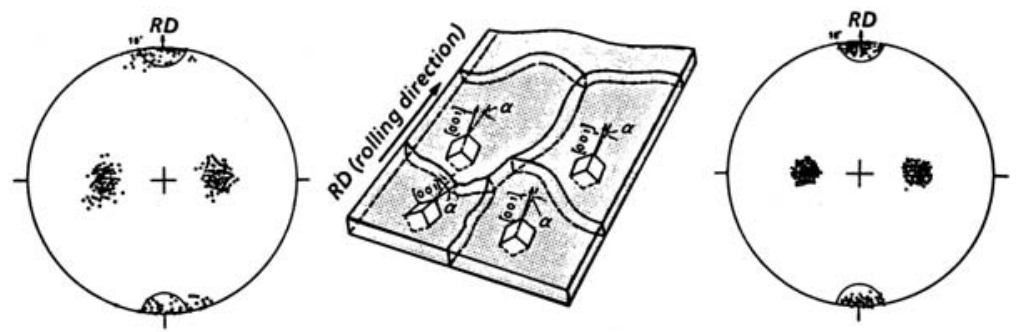

Figure 11. $\{100\}$ pole figures representing the orientation distribution of secondary recrystallized grains in the conventional grade (left) and the high permeability grade (right) of silicon steel. The small circles indicate an angular deviation of $10^{\circ}$ from the rolling direction. The central figure shows the Goss texture with a misorientation $(\alpha)$ of $\langle 001\rangle$ axis from the rolling direction (Matsuo 1989). 


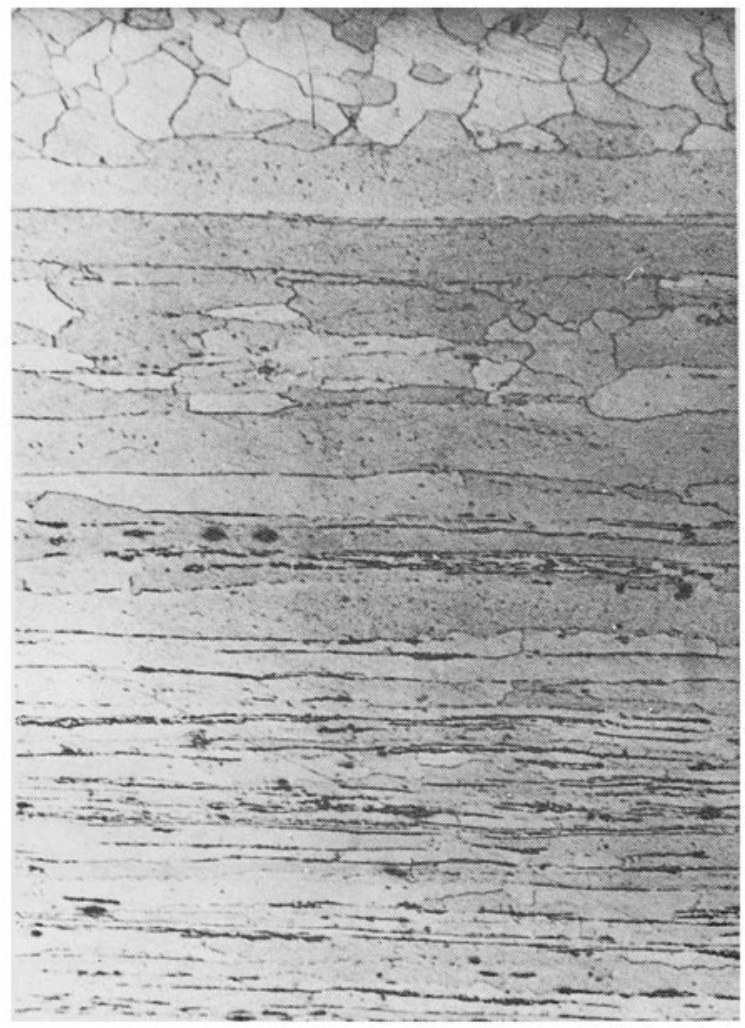

Figure 12. Longitudinal section micrograph (surface to centre) of hot-rolled strip of regular material, $100 \times($ Mishra et al 1984a).

cold reduction, in contrast to the single stage cold reduction for the type 1 and type 3 HGO.

Much of the early work on textures in silicon steels was concerned with the nature of the primary recrystallized matrix in which secondary recrystallization took place. Fiedler (1958) was the first to recognize that a minor $\{011\}\langle 100\rangle$ component must be present in primary recrystallized matrix to serve as potential nuclei for secondary recrystallization. However, it was realized later on that metallurgical parameters in the early stages of the production process can strongly influence the final texture, e.g. Dillamore and Katoh (1974). This appears to have prompted at least four different groups of investigators in the 1980 s to undertake independent studies right from the hot rolling stage, i.e. Mishra et al (1984a, 1986), Matsuo et al (1986), Inokuti et al $(1985,1987)$ and Shimizu et al $(1986)$. In particular, Mishra and his associates followed up with the processing sequence all the way to final secondary recrystallization. This was emulated by Zhong-Hai et al (1990) who also confirmed the results obtained by Mishra et al.

The microstructure of hot-rolled silicon steel of RGO variety (two-stage cold rolling) is shown in longitudinal section from surface to centre $(1 \mathrm{~mm})$ in figure 12 (Mishra et al 1984a). One recognizes right away that the outer layers are recrystallized whereas the interior largely retains a deformation structure. Figure 13 (Mishra et al 1984a) 

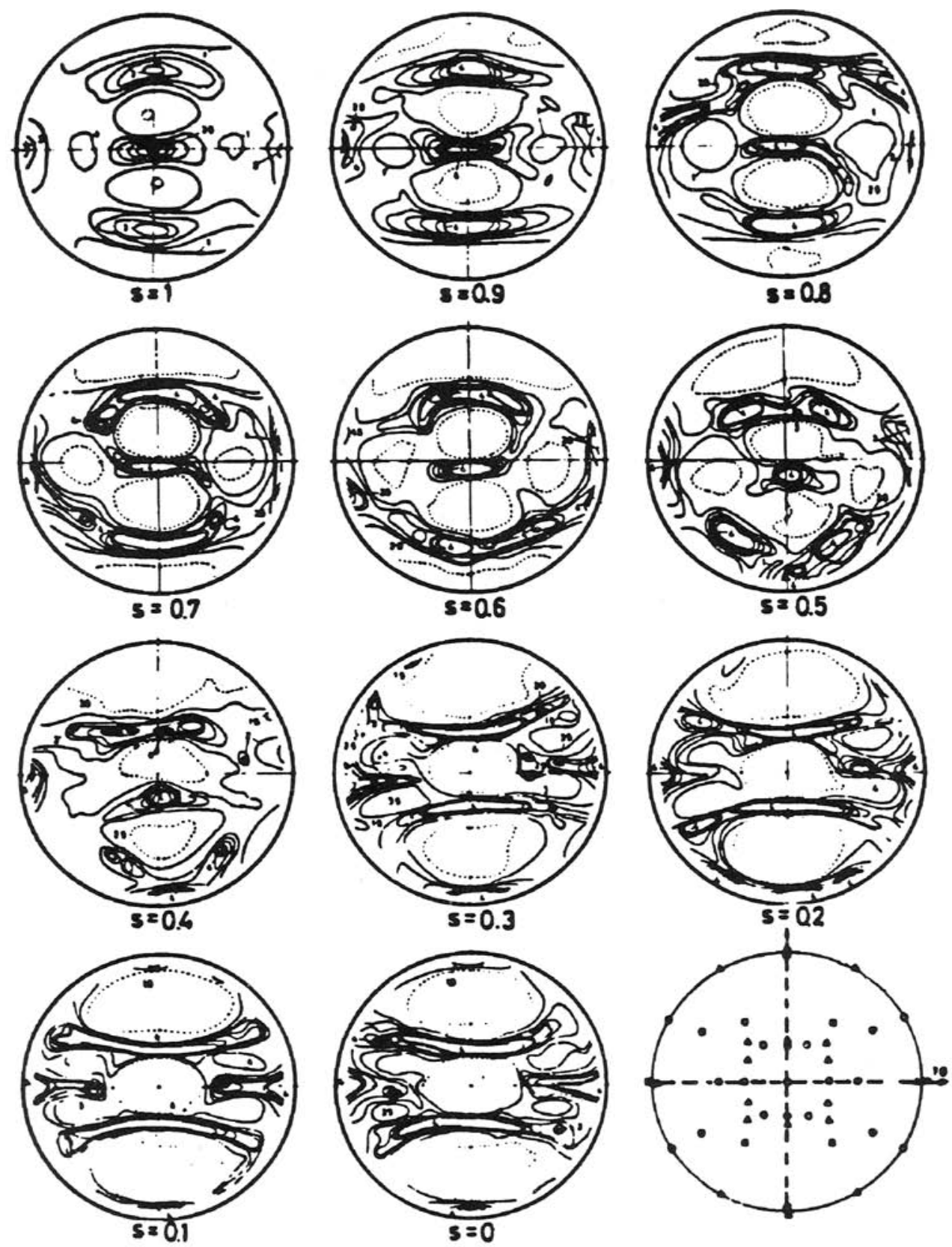

\section{Hot Band}

Figure 13. Through-thickness variation of texture from surface $(s=1)$ to centre $(s=0)$ of the hot-rolled strip of figure 12, as revealed in $\{110\}$ pole figures (Mishra et al 1984a). 


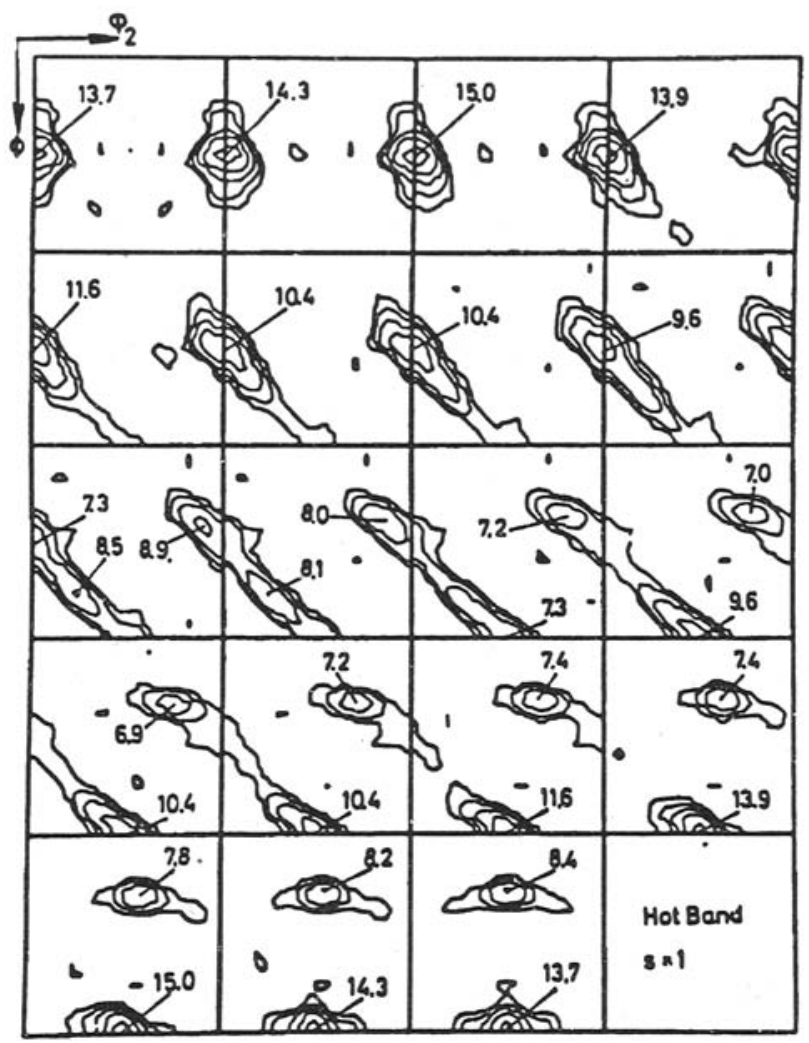

Figure 14. ODF for outer layers of hot strip of figures 12 and 13 (Mishra et al 1984a).

shows the through-thickness variation of texture from surface $(s=1)$ to centre $(s=0)$. The presence in the surface and sub-surface layers of a strong $\{011\}\langle 100\rangle$ orientation and in the centre layers of a strong $\{001\}\langle 110\rangle$ orientation may be noted. This represents a full $90^{\circ}$ rotation around the transverse $\langle 011\rangle$ axis from $s=1$ to $s=0$ level, which is a very remarkable feature.

In figure 14 (Mishra et al 1984a), the ODF for the surface layers for the same steel is shown. The main structural element in this ODF is an orientation tube of high intensity which begins at the Goss position, $\phi_{1}=0, \phi=45, \phi_{2}=0$, or 90 , and continues in Euler space along $\xi$, then along the line $\chi$ (figure 3, table 1) and finally ends at $\{4411\}\langle 11118\rangle$. This path, incidentally, includes all stable end orientations for shear deformation of bcc metals and hence the results lead one to conclude that the principal mode of deformation on the hot-rolled strip surface is shear (Mishra et al 1984a), caused presumably by the high temperature of rolling and high friction between rolls and metal. Once the Goss orientation forms on the surface and sub-surface layers by shear, it recrystallizes by dynamic in situ recrystallization and subsequently grows towards the centre layers of the strip (Mishra et al 1984a), thus resulting in the large grains seen in figure 12.

The $\phi_{1}=0^{\circ}$ section of the ODF contains many important orientations of interest including the Goss position (figure 2) and therefore, such sections have been selected and put together in figure 15 (Mishra et al 1984a) for the regular material through 
different stages of processing. As may be noted, in the central layers the texture composition of the hot-rolled strip (mainly $\{001\}\langle 110\rangle,\{112\}\langle 110\rangle$ and $\{111\}\langle 110\rangle$, all falling along the orientation tube $\alpha$ in figure 3) remained essentially "inherited" through hot band annealing and first-stage cold rolling.

Inhomogeneity of texture through the thickness persisted even after first-stage cold rolling (Mishra et al 1984a). Apart from the $\alpha$ fibre in the surface and in the centre, an additional fibre $\gamma$, i.e. $\langle 111\rangle \| N D$, was formed in the surface. This can be explained on the basis of earlier results (Dunn 1953; Taoka et al 1966) of single crystal experiments: the orientations near $\{011\}\langle 100\rangle$ rotate around TD towards $\{111\}\langle 112\rangle$ and near $\{4411\}\langle 11118\rangle$ orientations move to $\{001\}\langle 110\rangle$.

The microstructure after intermediate annealing indicated full recrystallization through the sheet thickness (Mishra et al 1984a). The most interesting feature, however, was the reappearance of the Goss component in the surface layers (figure 15). The reemergence of the $\{011\}\langle 100\rangle$ orientation is consistent with the single crystal work of Dunn (1953) who showed that a Goss-oriented single crystal of Fe-3\% Si upon cold rolling and annealing recrystallizes back to its original orientation. As may be noted in figure 15 , the Goss orientation disappeared on second cold rolling and reappeared again after primary recrystallization. The perpetuation of the Goss orientation through successive stages of processing has been termed as "texture memory" effect by Mishra et al (1984a). This effect, as also the inheritance of texture, as first proposed by Mishra et al (1984a) have been confirmed by several investigators (Abbruzzese et al 1991; Gangli et al 1991; Bottcher and Lucke 1993).

Whereas full-scale secondary recrystallization to $\{011\}\langle 100\rangle$ occurred when a primary recrystallized strip was finally annealed at $1050^{\circ} \mathrm{C}$, figure 16 (Mishra et al 1984a), only very limited secondary recrystallization took place in a similarly preprocessed steel whose surface layers were removed (after primary recrystallization) before subjecting to annealing at $1050^{\circ} \mathrm{C}$, figure 17 (Mishra et al 1984a). This strongly suggests that the Goss nuclei capable of growth were predominantly in the surface and sub-surface layers.

It may be emphasized that the appearance of the Goss orientation on the surface layers (figure 15) was always associated with a reduction in the intensity of the $\{111\}$ $\langle 112\rangle$ component. Also, in the primary recrystallized matrix the $\{111\}\langle 112\rangle$ was a major component. These findings are of significance in the context of the observations by Ibe and Lücke $(1966,1968)$ that in $\mathrm{Fe}-3 \% \mathrm{Si}$ a preferred $27^{\circ}$ rotational relationship around a $\langle 110\rangle$ pole exists for growth selection. In the present case the $\{111\}\langle 112\rangle$ orientation is related to $\{011\}\langle 100\rangle$ by a $35^{\circ}$ rotation around the $\langle 110\rangle$ transverse axis. It would, therefore, appear that during secondary recrystallization, the grains with $\{011\}\langle 100\rangle$ Goss orientation grow first at the expense of the $\{111\}\langle 112\rangle$, thereby assuming a size advantage, and then consume all other matrix grains progressively from surface to centre. Such an idea is compatible with Beck's theory of oriented growth (Beck 1954) which has, as its basis, the orientation dependence of grainboundary mobility.

In the foregoing paragraphs the interesting results obtained with RGO variety material (two-stage cold rolling) was dealt with. Texture development in oriented silicon steel with one-stage cold rolling (high permeability steel, HGO) has also been the subject of many studies in the recent past. Most of these investigations focused on steels using AlN plus MnS as grain growth inhibitor, notable amongst these studies being the works of Mishra and coworkers (Mishra et al 1984, 1986; Mishra 1993) and 

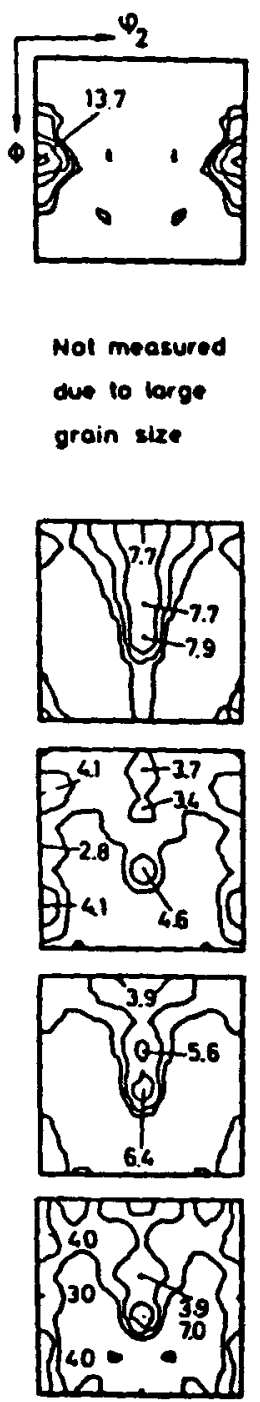

$5=1$
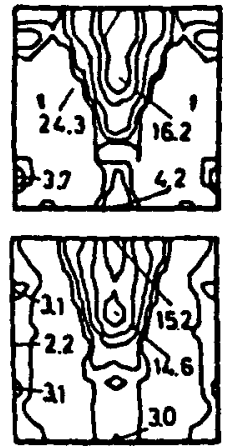

Annealed

Mat and

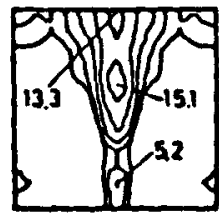

First

Cold Rolling
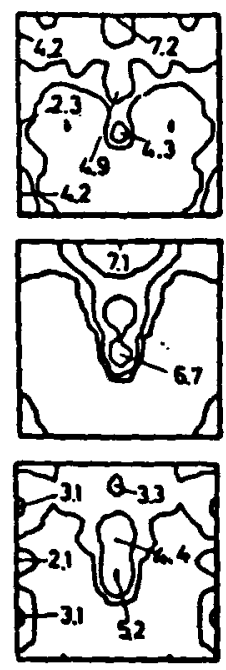

$5=0$
Second

Cold Rolling

Inlermediate

Anneding

Primory

Reerystolliard

Figure 15. ODF sections for $\phi_{1}=0$, for surfaces $(s=1)$ and central layers $(s=0)$ through successive stages of processing of steel of figures 12-14 (Mishra 1984).

Matsuo et al (1986) who independently investigated the origin of the Goss orientation and through-thickness texture variation in successive stages of processing of such steels. Mishra et al (1986) also attempted, for the first time, a comparison between the mechanism of texture development in the single and two-stage cold rolling routes. The results obtained by them for HGO were very similar to those for RGO; however, Mishra et al (1986) have pointed out some significant differences. Thus, in the case of the latter (RGO), whereas the Goss orientation was predominantly present in the surface and sub-surface layers in all annealed states (annealed hot strip, intermediate annealed and primary recrystallized), it also had a presence, though weak, in the central layers. On the other hand in the case of the latter (HGO), no Goss intensity 


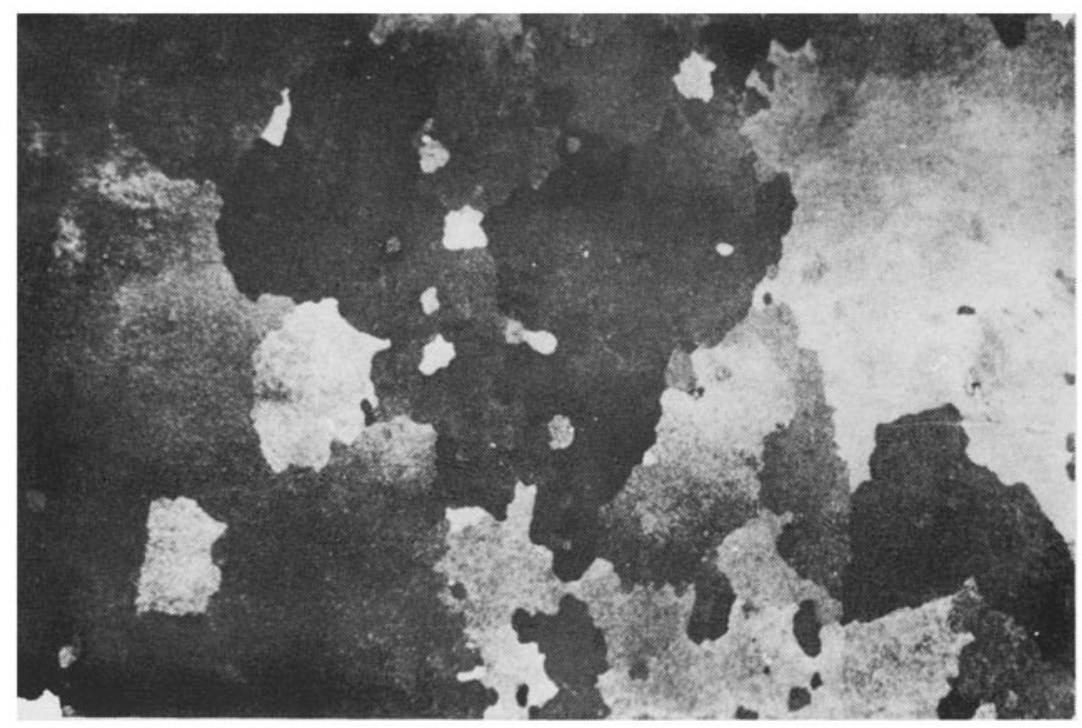

Figure 16. Surface macrograph $(3 x)$ of fully secondary recrystallized strip of steel of figures 12-15 (Mishra et al 1984a).

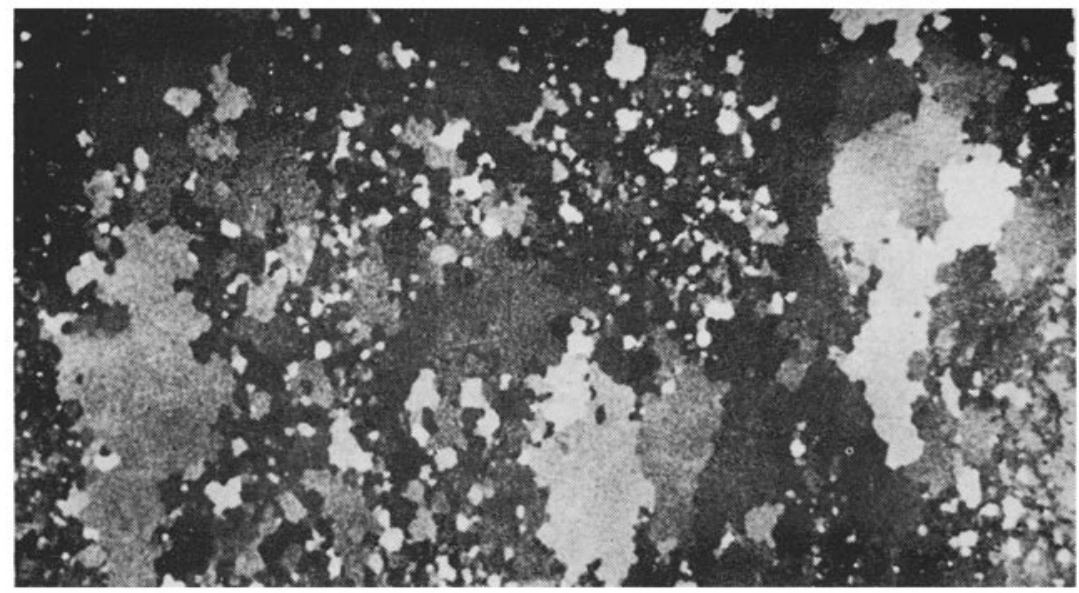

Figure 17. Surface macrograph $(2 \times)$ of partially secondary recrystallized strip of steel of figures 12-16 (whose surface layers were removed by chemical etching from both sides before final annealing) (Mishra et al 1984a).

was observed for the central layers either in the annealed hot band or after primary recrystallization, i.e. in the single-stage cold-rolled steel (HGO), the Goss nuclei capable of growth are present only in the outer layers of the strip. Thus, in effect, the population of Goss nuclei in the single-stage route is smaller, as compared to the two-stage route. This situation may have a bearing on the fact that larger grain sizes and a sharper texture (about 3 degrees misorientation) are generally achieved from the single stage than from the two-stage route (about 7 degrees misorientation). 


\section{Conclusions}

The principal features of texture formation in low-carbon steels can be summarized as follows:

(A) Preferred orientations can be described by using two concepts: (i) peak-type components around certain low-index ideal orientations, and (ii) complete or limited fibres.

(B) In deep drawing steels, the most important fibre is the $\langle 111\rangle \| N D$, which is present as a complete and almost ideal orientation tube. The most desirable texture components, from the point of view of press forming, are $\{111\}\langle 110\rangle,\{111\}\langle 112\rangle$ and $\{554\}\langle 225\rangle$.

(C) In silicon steels, the genesis of the sharp Goss texture lies in the Goss-oriented grains already formed, by a mode of shear deformation during hot rolling, in the surface layers of the hot-rolled strip.

This texture is "inherited" during subsequent processes of annealing, cold rolling, primary recrystallization annealing and secondary recrystallization annealing.

The disappearance of the Goss component on cold rolling and reappearance on annealing represents a "texture memory effect" and this phenomenon parallels the earlier known behaviour of single crystals of $\mathrm{Fe}-3 \% \mathrm{Si}$ with $\{011\}\langle 100\rangle$ initial orientation.

Secondary recrystallization proceeds from the surface to the centre.

\section{Acknowledgements}

Prof. Paul A Beck at the University of Illinois introduced the author to the subject of textures. Prof. K Lücke of the Aachen Technical University in West Germany contributed many ideas. Dr C Därmann worked along in obtaining experimental results. The author is thankful to all of them. The author is also grateful to the Alexander von Humboldt Foundation and the Steel Authority of India Limited for supporting his work on textures for more than a decade.

\section{References}

Abbruzzese G, Campopians A and Fortunati S 1991 Textures \& Microstructures 14-18 775

Beck P A 1954 Adv. Phys. 3245

Bottcher A and Lücke K 1993 Acta Metall. 412503

Bozorth.R M 1935 Trans. Am. Soc. Met. 231107

Bunge H J 1965 Z. Metallkd 56872

Bunge H J 1969 Mathematische methoden der texturanalyse (Berlin: Akademie)

Därmann C, Mishra S and Lücke K 1984a in Textures of materials, ICOTOM 7 (eds) C M Brakman, P Jongenburger and E J Mittemeijer (Holland: Netherland Society for Materials Science) 47

Därmann C, Holscher M, Mishra S and Lücke K 1984b in Textures of materials, ICOTOM 7 (eds) C M Brakman, P Jongenburger and E J Mittemeijer (Holland: Netherland Society for Materials Science) 759

Dillamore I L and Katoh H 1974 Met. Sci. 8121

Dunn C G 1949 in Cold working of metals (Cleveland Ohio: Am. Soc. Metals) 113

Dunn C G 1953 Acta Metall. 1163 
Fiedler H C 1958 J. Appl. Phys. 29361

Gangli P, Szpunar J and Golini F 1991 Textures \& Microstructures 14-18 819

Goss N P 1935 Trans. Am. Soc. Met. 23511

Held J F 1965 First Operating Metallurgy Conf. of AIME, Pittsburgh, USA

Hu H 1978 in Textures of materials (eds) G Gottstein and K Lucke (Berlin: Springer-Verlag) 23

Hutchinson W B 1984 Int. Metall. Rev. 2925

Hutchinson W B and Ushioda K 1984 Scand. J. Metall. 13269

Ibe G and Lücke K 1966 in Recrystallization, grain growth and textures (ed.) H Margolin, Am. Soc. Metals, Metals Park, Ohio 434

Ibe $\mathrm{G}$ and Lücke K 1968 Arch. Eisenhutt 39693

Inokuti Y, Maeda C and Ito Y 1985 Metall. Trans. A16 1613

Inokuti Y, Maeda C and Ito Y 1987 Trans. ISIJ 27139

Irie T, Satoh S, Yasuda A and Hashimoto O 1982 in Metallurgy of continuous annealed sheet (eds) B L

Bramfitt and P L Mangonon Jr (Pennsylvania: Warrendale, TMS-AIME, USA) 3

Lankford W T, Snyder S C and Bauscher J A 1950 Trans. ASM 421197

Lotter U, Mueschenborn K and Knorr R 1978 Trans. ASM 42285

Matsuo M, Sakai T and Suga Y 1986 Metall. Trans. A17 1313

Matsuo M 1989 ISIJ Int. 29809

May J E and Turnbull D 1958 Trans. Am. Inst. Min. Met. Engrs, 212769

Mishra S and Därmann C 1982 Int. Metall. Rev. 27307

Mishra S 1990 Indian J. Technol. 28452

Mishra S, Därmann C and Lücke K 1984a Acta Metall. 322185

Mishra S 1984 in Recent advances in materials research (ed.) C M Srivastava (New Delhi: Oxford \& IBH Publ.) 105

Mishra S, Därmann C and Lücke K 1986 Met. Trans. A17 1301

Mishra S 1993 in Interfaces, structure and properties (eds) S Ranganathan, C S Pande, B B Rath and D A Smith (Switzerland: Trans. Tech. Pub. Ltd.) 351

Mishra S, Därmann C and Lücke K 1983 Met. Trans. A14 11

Mishra S 1983 Trans. Indian Inst. Metals 3636

Mishra S 1984 in Proceedings of the third Indo-Soviet bilateral Symposium on improvement in technology and quality of finished products in iron and steel industry-problems and prospects, Ranchi, 268

Mishra S, Paul S K and Nandi R K 1985 in Proceedings of the Fourteenth Congress of the International Deep Drawing Research Group, Cologne, FRG

Mishra S, Därmann C and Lücke K 1984 in Textures of materials, ICOTOM 7 (eds) C M Brakman, P Jogenburger and E J Mittemeijer (Holland: Netherland Society for Materials Science) 269

Roe R J 1965 J. Appl. Phys. 362024

Shimizu Y, Ito Y and lida Y 1986 Metall. Trans. A17 1323

Taoka T, Furubayashi E and Takeuchi S 1966 Trans. ISIJ 6290

Willis D J and Hatherly M 1976 in Textures and properties of materials (ed.) J Davies (London: The Metals Society) 48

Whiteley R L, Wise D E and Blickwede D J 1961 Sheet Met. Ind. 38349

Whiteley R L 1960 Trans. ASM 52154

Whiteley R L and Wise D L 1962 in Flat products (New York: AIME) Vol. III

Zhong-Hai Y, Yi-Fan X and Jai G 1990 Acta Metall. 381023 